\title{
Revisão: Conceitos de dispersão e empacotamento de partículas para a produção de concretos especiais aplicados na construção civil
}

\author{
(Review: Concepts of particle dispersion and packing for \\ special concretes production)
}

\author{
A. L. de Castro, V. C. Pandolfelli \\ Departamento de Engenharia de Materiais - DEMa, Universidade Federal de S. Carlos, \\ Rod. Washington Luiz, km 235, S. Carlos, SP 13565-905 \\ alelorencastro@yahoo.com.br,vicpando@power.ufscar.br
}

\begin{abstract}
Resumo
O concreto material de construção mais amplamente utilizado está constantemente evoluindo. Nos últimos anos, muitas pesquisas têm sido desenvolvidas e a busca por materiais com desempenho mecânico e de durabilidade cada vez maiores tem sido o alvo dos pesquisadores da tecnologia dos concretos. Tais materiais permitem que os projetistas e arquitetos o usem eficientemente em edifícios altos, além de serem esteticamente mais interessantes. Para tanto, concretos obtidos a partir da engenharia de microestrutura são necessários. Por serem compósitos constituídos de partículas com granulometria fina (tamanho máximo $\leq 4750 \mu \mathrm{m}$ ) e uma baixa relação água/cimento, esses concretos apresentam matrizes densas obtidas a partir da otimização do empacotamento dos materiais granulares, enquanto a trabalhabilidade adequada é obtida com a dispersão das partículas promovida pela incorporação de aditivos químicos à mistura. Além disso, utilizam adições minerais que são, na grande maioria, subprodutos industriais, resultando em um grande benefício ambiental: reciclagem de resíduos industriais, redução de emissões poluidoras durante a produção do cimento, preservação de matérias-primas e economia de energia. Assim, no presente artigo, uma revisão sobre os conceitos de dispersão e empacotamento de partículas foi realizada, direcionando-se para os concretos especiais aplicados na construção civil.
\end{abstract}

Palavras-chave: engenharia de microestrutura, dispersão e empacotamento de partículas, concretos especiais.

\begin{abstract}
Concrete, the most widely used construction material, is constantly developing. During the recent years, several researches have been carried out and the search for materials with higher mechanical and durability performance has been the objective of the concrete technology area. These materials allow designers and the architects to use them efficiently in high slender and innovative buildings. Therefore, in order to attain this target, microstructural engineering is required. Being composites constituted of fine size distribution particles (maximum size $\leq 4750 \mu \mathrm{m}$ ) and low water/cement ratio, these concretes present dense matrix by packing optimization of the granular materials, whereas the suitable workability is the result of particle dispersion promoted by adding chemical admixtures to the mixture. Moreover, they incorporate mineral additives which are, mostly, industrial by-products, resulting in a great environmental benefit: industrial residues recycling, pollutant emissions reduction during cement production, raw materials preservation and energy saving. Thus, in present paper, a review related to the concepts of particle dispersion and packing was carried out, addressed for special concretes applied in the civil engineering field.

Keywords: microstructure engineering, particle dispersion and packing, special concretes.
\end{abstract}

\section{INTRODUÇÃO}

Os concretos especiais atuais são mais do que uma simples mistura de cimento, água e agregados, pois freqüentemente contêm aditivos químicos e adições minerais que fornecem uma variedade de propriedades e características especiais ao material. Estes concretos também estão se tornando bastante complexos, uma vez que produtos minerais e amorfos além do clínquer - interagem com moléculas orgânicas ou polímeros desenvolvidos especialmente para realçar certas propriedades ou para corrigir algumas deficiências dos cimentos existentes [1].
Nos últimos anos, muitas pesquisas têm sido desenvolvidas na área dos concretos, onde os pesquisadores buscam cada vez mais materiais com desempenhos superiores em termos de comportamento mecânico e durabilidade. Mais recentemente, duas linhas principais de pesquisa têm sido seguidas: a primeira envolve concretos adensados com pequenas partículas (DSP - Densified with Small Particles), compostos por altos teores de aditivo superplastificante e sílica ativa e agregados muito resistentes - granito ou bauxita calcinada; e a segunda linha está relacionada com pastas de cimento sem macrodefeitos (MDF - Macro Defect Free), contendo polímeros e cimentos aluminosos. Nos anos 
90, o concreto com pós reativos (RPC - Reactive Powder Concrete) foi desenvolvido tendo como matérias-primas a sílica ativa, o pó de quartzo e a fibra metálica, atingindose resistência à compressão que varia entre $200 \mathrm{MPa}$ e 800 $\mathrm{MPa}$ [2].

Esses concretos especiais são materiais à base de cimento desenvolvidos por meio da engenharia de microestrutura. Por serem compósitos constituídos de partículas com granulometria fina (tamanho máximo $\leq 4750 \mu \mathrm{m}$ ) e uma baixa relação água/cimento, apresentam matrizes densas obtidas a partir da otimização do empacotamento dos materiais granulares, enquanto a trabalhabilidade adequada é alcançada por meio da dispersão das partículas promovida pela incorporação de aditivos químicos à mistura.

Assim, a produção de concretos com trabalhabilidade adequada (quando no estado fresco) e alta resistência mecânica e durabilidade (quando no estado endurecido) é possível devido à associação de aditivos superplastificantes e adições minerais. Os superplastificantes permitem a obtenção de misturas com baixa relação água/cimento (menor que 0,30), enquanto as adições minerais, com grãos de tamanhos menores que as partículas de cimento, facilitam a produção associando seu efeito físico (efeito fíler) ao efeito químico (reação pozolânica) [3].

Assim, no presente artigo, uma revisão sobre os conceitos de dispersão e empacotamento de partículas foi realizada, direcionando-se para os concretos especiais aplicados na construção civil.

\section{DISPERSÃO DE PARTÍCULAS}

As partículas de cimento apresentam uma grande tendência à aglomeração quando entram em contato com um líquido tão polar quanto a água, devido a vários tipos de interação: forças de atração interpartículas (forças de van der Waals), forças eletrostáticas entre posições de sítios com cargas opostas e forte interação ou ligação envolvendo as moléculas de água ou hidratos. Assumir tal estrutura aglomerada implica na retenção de certa quantidade da água de mistura e, com isso, na geração de uma rede aberta de canais entre as partículas. Essa rede de vazios pode aprisionar parte da água que, por essa razão, fica indisponível para hidratar a superfície das partículas de cimento e para fluidificar a mistura [4].

Os aglomerados formados, permanentes ou não, além de influenciar a reologia das suspensões, podem interferir no empacotamento e, conseqüentemente, na microestrutura do material. Com isso, são gerados produtos com maior incidência de defeitos e com microestruturas heterogêneas. Assim, os aglomerados devem ser eliminados, buscando sempre suspensões dispersas que, além de apresentarem menor viscosidade, permitem a utilização de maiores concentrações de sólidos no processo. Nestas suspensões, as partículas encontram-se individualizadas, sendo pouco influenciadas pela ação da gravidade, permitindo que permaneçam homogêneas e estáveis por um maior período de tempo [5].
Para se obter suspensões dispersas, as forças de repulsão entre as partículas devem superar as forças de atração. Assim, o uso de dispersantes torna-se necessário para evitar a sedimentação de partículas e conseqüente segregação de fases, possibilitando a preparação de suspensões homogêneas com alta concentração de sólidos. Esses aditivos são eficientes na desaglomeração das estruturas de partículas de cimento e em sua dispersão, evitando uma ligação prematura, minimizando a quantidade de água necessária para a adequada trabalhabilidade da suspensão e resultando em misturas trabalháveis pelo intervalo de tempo necessário à sua aplicação.

\section{Aditivos superplastificantes}

Um concreto durável é caracterizado como um material com baixa porosidade, no qual os grãos individuais de cimento estão densamente empacotados antes do início da hidratação. Normalmente esse concreto é caracterizado por uma baixa relação água/cimento, que é responsável pelas propriedades mecânicas superiores e pela maior durabilidade. Porém, o uso de uma baixa relação água/cimento implica na redução da trabalhabilidade ou na utilização de um alto teor de cimento para a finalidade desejada. Além disso, para aplicação, um concreto necessita de muito mais água do que apenas para a hidratação do cimento, o que resulta em certa porosidade no concreto endurecido, reduzindo o potencial de suas propriedades mecânicas e facilitando a degradação desse material. Pela adição de pequenas quantidades de aditivos poliméricos - superplastificantes - pode-se diminuir consideravelmente a quantidade de água necessária para a obtenção da trabalhabilidade desejada e, conseqüentemente, a porosidade, melhorando a durabilidade do concreto [6].

Os aditivos superplastificantes foram utilizados pela primeira vez em concreto no final dos anos 60, simultaneamente no Japão e na Alemanha. Durante os anos 80 , suas dosagens foram aumentadas pouco a pouco, até que se percebeu que eles poderiam ser usados como excelentes redutores de água [7]. Assim, com o avanço da tecnologia do concreto - desenvolvimento de misturas com uma maior densidade de empacotamento, com menores teores de cimento e água etc. - o uso de aditivos químicos se tornou essencial para a produção de misturas de alto desempenho.

De acordo com a NBR 11768/92 [8], os aditivos superplastificantes (tipo SP), também chamados de aditivos redutores de água de alta eficiência pela norma americana ASTM C-494/92 [9], são definidos como os produtos que aumentam o índice de consistência do concreto, mantendose a quantidade de água de mistura constante, ou ainda, como aqueles que possibilitam a redução mínima de $12 \%$ da água de mistura na produção de um concreto com uma dada consistência.

Os aditivos superplastificantes são polímeros orgânicos hidrossolúveis - com moléculas longas e de massa molecular elevada - obtidos sinteticamente por meio de um processo de polimerização complexo. A primeira geração de superplastificantes foi baseada em condensados sulfonados 
de naftaleno-formaldeído e/ou condensados sulfonados de melanina-formaldeído, dispersantes poliméricos baseados em uma única unidade repetitiva, não permitindo grandes variações de sua estrutura molecular. Mais recentemente, uma nova geração de aditivos superplastificantes - à base de policarboxilatos com moléculas de poliéteres pendentes - tem se tornado mais comum. Esses aditivos são baseados em duas ou mais unidades estruturais que proporcionam uma maior diversidade das possíveis estruturas moleculares. Como exemplo, a quantidade relativa de unidades aniônicas por unidades de poliéteres pode ser variada, o peso molecular da molécula de poliéter pode ser variado e o peso molecular da cadeia principal de policarboxilato também pode ser ajustado para a criação de polímeros com diferentes características de desempenho $[10,11]$.

A maioria dos diferentes tipos de superplastificantes são polieletrólitos, um tipo de dispersante comumente utilizado em cerâmicas, tintas e refratários. Os polieletrólitos se adsorvem na interface sólido-líquido e impõem forças de repulsão, reduzindo ou eliminando a adesão entre as partículas vizinhas. A adsorção dos polieletrólitos é dependente das interações eletrostáticas entre eles e a superfície das partículas. Sendo assim, a química da superfície de uma fase sólida e as propriedades da solução dos polieletrólitos são parâmetros importantes controlados pelo pH e pela força iônica [12].

As vantagens de se utilizar aditivos químicos incluem a produção de concretos com alta trabalhabilidade, o que facilita a manipulação, a aplicação e o adensamento do material e a produção de concretos de alto desempenho com uma menor quantidade de água, alta resistência e boa durabilidade [13-15]. Dessa maneira, os aditivos superplastificantes melhoram as propriedades do concreto nas primeiras idades sem promover qualquer efeito adverso para tempos mais longos, particularmente quando usado em misturas de concreto de alto desempenho [16].

Além disso, a ação dispersante permite que uma maior porção da área superficial do cimento entre em contato com a água de mistura, aumentado a taxa de hidratação e, conseqüentemente, a resistência inicial do material. Com a redução da relação água/cimento, uma matriz mais densa e menos permeável é obtida, não retardando apenas a taxa de penetração de água e/ou agentes agressivos, mas também fornecendo uma maior resistência às tensões geradas pelos carregamentos internos e externos (melhor desempenho mecânico) [13, 17]. Os aditivos superplastificantes devem ser utilizados em dosagens apropriadas caso se deseje evitar efeitos secundários, os quais podem resultar em perdas rápidas e irrecuperáveis de abatimento, grande retardamento da pega e segregação severa ou exsudação excessiva [18].

Muitos fatores influenciam a fluidez e o processo de hidratação de materiais à base de cimento e alguns deles também podem ter efeitos de sinergia. Assim, a eficiência de um aditivo depende de vários fatores, tais como a composição química do próprio aditivo e do cimento, o teor de sulfato álcali solúvel, a dosagem, os componentes e a proporção da mistura, o tempo e a temperatura do concreto, e o momento de incorporação do aditivo [11, 15, 17, 19-21].

Além dos superplastificantes serem produzidos a partir de diferentes grupos básicos (ácido lignossulfônico, ácido sulfônico de melanina-formaldeído e/ou de naftalenoformaldeído e ácido policarboxílico), também pode-se observar diferenças entre aditivos de um mesmo grupo dependendo de sua síntese, o que influencia o peso molecular e a configuração química $[22,23]$. O peso molecular de um superplastificante é de fundamental importância para sua eficiência na redução de água de misturas à base de cimento: polímeros com baixo peso molecular tendem a permanecer em solução, enquanto polímeros com pesos moleculares maiores são adsorvidos sobre as partículas de cimento, influenciando tanto as propriedades de dispersão quanto a morfologia dos produtos da hidratação do $\mathrm{C}_{3} \mathrm{~A}[4,24]$.

A eficiência do superplastificante não está condicionada apenas por sua compatibilidade com o cimento, mas também pelas técnicas de mistura e transporte, pela correta dosagem, pela metodologia de incorporação, pelas condições ambientais e por uma total compreensão de todas as vantagens que podem ser obtidas com o seu uso.

Mesmo que um aditivo aumente a densidade potencial da superfície das partículas e esse efeito seja perdido após um determinado período de tempo, sua adição não prejudicará a pega e o endurecimento do cimento, salvo quando são usados na presença de cimentos com baixo teor de $\mathrm{C}_{3} \mathrm{~A}$ (neste caso, pode-se observar um retardamento excessivo da pega do sistema). Além disso, esses aditivos não têm influência sobre a retração, a fluência, o módulo de elasticidade, as resistências ao gelo/degelo e aos sulfatos do concreto, assim como não apresentam qualquer efeito sobre a durabilidade do mesmo [25].

Nem todos os cimentos que cumprem as especificações regulamentares têm o mesmo comportamento reológico com um dado superplastificante quando se trabalha com baixas relações água/cimento. Da mesma maneira, nem todos os superplastificantes que cumprem as especificações de normas interagem da mesma forma com um dado cimento. Assim, os aditivos superplastificantes não são onipotentes: existem problemas importantes de incompatibilidade entre pares de cimento-superplastificante, tais como o endurecimento imediato do concreto (falsa pega), a variação ou a redução da fluidez inicial e/ou o retardamento excessivo da pega [19, 26].

Existem diversas causas para a fluidez anormal decorrente dos problemas de incompatibilidade cimentoaditivo. Como o aditivo é indispensável para a produção dos concretos especiais, os problemas de incompatibilidade podem ser amplamente divididos em dois grupos: problemas causados pelo efeito da incorporação de aditivo sobre a reação de hidratação do cimento e os problemas causados pela adsorção do aditivo sobre as partículas de cimento [26]. A quantidade de álcalis solúveis que entram em solução durante os primeiros minutos da hidratação também pode ser considerada um ponto fundamental na compatibilidade cimento-aditivo [19].

Para misturas com baixa relação água/cimento, a 
compatibilidade cimento-aditivo não pode ser determinada somente a partir das especificações de cada material; é necessária a avaliação experimental da mistura devido aos complexos fenômenos químicos envolvidos. Para isso, diversos métodos de ensaio foram desenvolvidos e, quando empregados de maneira adequada, é possível fazer uma primeira escolha do aditivo a ser usado, de modo a determinar as combinações eficientes e ineficientes. A escolha do superplastificante deve ser baseada na relação custo-eficiência obtida por meio de comparações entre as curvas "tempo de escoamento versus dosagem de superplastificante" e por meio da determinação do ponto de saturação desse aditivo (Fig. 1) [27].

Geralmente, o tempo de escoamento diminui com o aumento do teor de superplastificante até o chamado ponto de saturação, a partir do qual já não diminui significativamente. Esta dosagem é definida como ótima, ou seja, é o ponto em
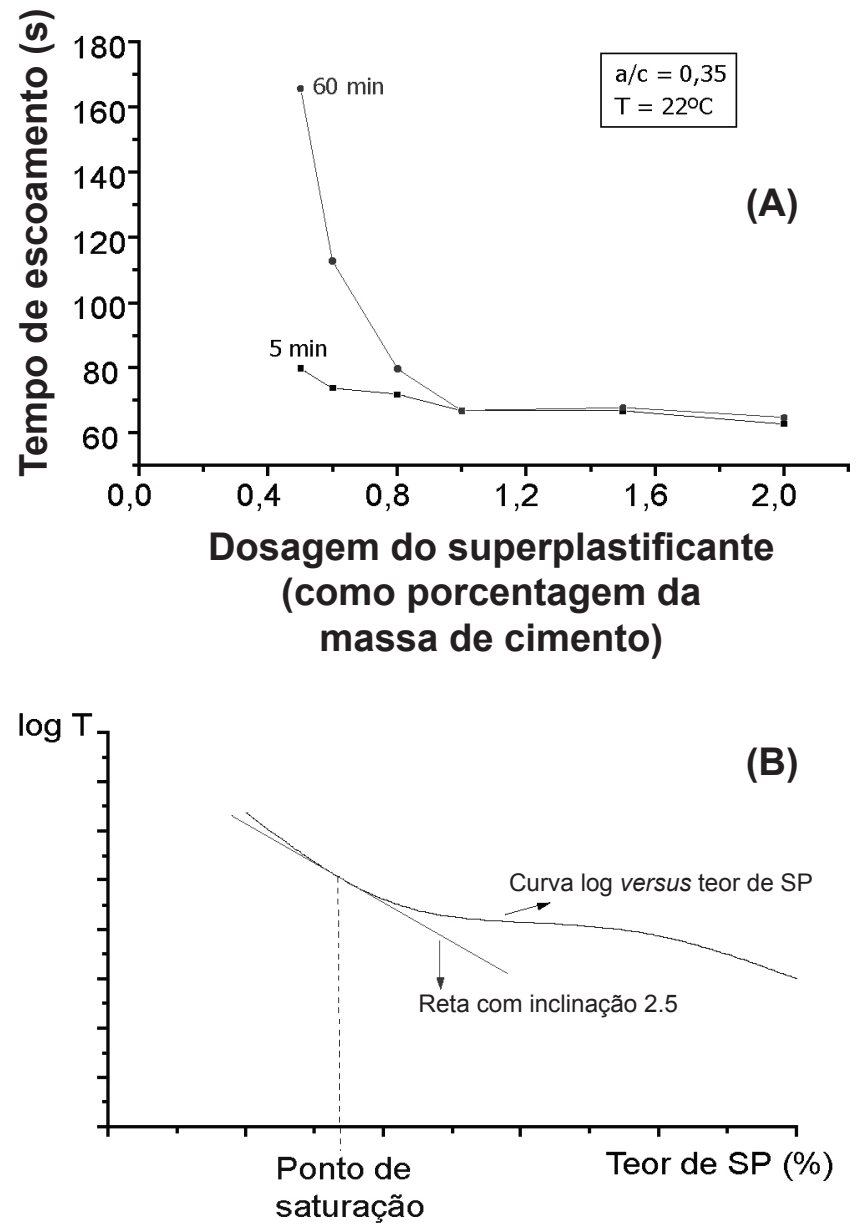

Figura 1: Exemplos de métodos utilizados para a determinação do ponto de saturação do aditivo superplastificante. A: método apresentado por Aïtcin [7]; B: método AFREM [28]. Obs.: $\log \mathrm{T}$ corresponde ao logaritmo do tempo de escoamento; SP: superplastificante.

[Figure 1: Examples of methods used for the determination of superplasticizer saturation dosage. A: method presented by Aïtcin [7]; B: the AFREM method [28]. Obs.: log T corresponds to the logarithm of flow time; SP: superplasticizer.] que, nas condições experimentais consideradas para medir o tempo de escoamento, qualquer aumento na dosagem do aditivo não produz qualquer efeito significativo sobre a reologia da pasta de cimento [7]. O ponto de saturação de um superplastificante varia de um cimento para outro, quando usado o mesmo aditivo, e de um superplastificante para outro, quando usado o mesmo cimento. Ele depende do tipo de cimento (granulometria, quantidade e reatividade do $\mathrm{C}_{3} \mathrm{~A}$, do teor e da taxa de dissolução dos sulfatos), da relação água/cimento, do tipo de superplastificante, do tipo e da dosagem das adições minerais e da seqüência e tempo de mistura dos materiais constituintes $[4,27]$. Assim, com tantos fatores influenciando o comportamento de um superplastificante na presença de um determinado cimento, já se compreende que a simples dosagem recomendada por um produtor de aditivo tem pouco significado. Para cada combinação cimento-superplastificante e dosagem de mistura existirá uma dosagem ótima de aditivo.

\section{Interação cimento-superplastificante}

A natureza química do superplastificante influencia o comportamento de materiais à base de cimento quando no estado fresco. Porém, nenhuma tendência definitiva pode ser identificada a partir de uma pesquisa bibliográfica sobre as propriedades do material, como, por exemplo, a trabalhabilidade e sua perda ao longo do tempo, o retardamento da pega, o teor de ar incorporado etc. Isso indica claramente que diversas propriedades intrínsecas do superplastificante podem influenciar seu desempenho.

De acordo com algumas pesquisas, o fator chave que controla o comportamento do superplastificante é a composição do cimento, pois o efeito positivo desse aditivo só é verificado se ele reagir com os produtos da hidratação do cimento. Por um lado, isso pode ocorrer pelos efeitos de defloculação e dispersão do aditivo sobre as partículas de cimento e, por outro lado, pela influência sobre as taxas de

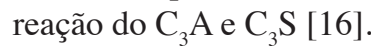

As reações de hidratação do cimento são muito complexas, não devido apenas às variações da composição, da morfologia das partículas e do processo de produção do cimento, mas também devido a outros possíveis fatores, tais como a área superficial do cimento, as condições ambientais e a presença de aditivos [29]. Nos concretos atuais, os aditivos químicos incorporados à mistura interagem com os vários constituintes do cimento e influenciam as reações de hidratação do mesmo. Para uma utilização satisfatória desses aditivos dentro de uma ampla variação de condições, é preciso conhecer os conceitos básicos da química do cimento e das interações cimento-aditivo. Assim, é necessário estudar o processo de hidratação do cimento para uma melhor compreensão da interferência do superplastificante.

O processo completo da hidratação e pega do cimento resulta de uma combinação das reações que se desenvolvem na solução, dos fenômenos interfaciais e das reações no estado sólido [30]. Para a visualização da influência dos aditivos sobre a hidratação do cimento, um esquema representando 
a evolução da hidratação do cimento ao longo do tempo é apresentado na Fig. 2, onde são identificados cinco estágios distintos da hidratação: I - Reação inicial (pré-indução), entre 0 e 15 min; II - Período de indução, entre 15 min e 4 h; III - Período de aceleração, entre 4 e 8 h; IV - Período de desaceleração e endurecimento, entre 8 e 24 h; V - Período de reação lenta e contínua (difusão), entre 1 e 28 dias.

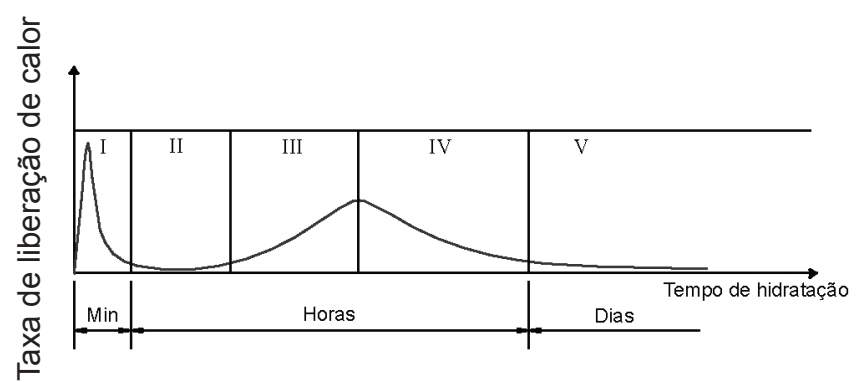

Figura 2: Adaptação de uma representação gráfica da hidratação do cimento pelo método da calorimetria [30].

[Figure 2: Adaptation of a graphical representation of the cement hydration by calorimetry method [30].]

Deve-se atentar principalmente para as etapas em que o superplastificante influencia o processo de hidratação, ou seja, os estágios I, II e III apresentados na Fig. 2. No estágio I, a presença do superplastificante, que interfere nos processos de nucleação e/ou crescimento dos produtos de hidratação, influencia a taxa da reação de hidratação, os produtos da reação ou ambos. No estágio II, a quantidade de íons sulfato $\left(\mathrm{SO}_{4}{ }^{2-}\right)$ disponível é que determina o comportamento do sistema cimentício, particularmente suas propriedades reológicas e seu tempo de início de pega. No estágio III, pode-se verificar uma situação de auto-inibição no comportamento da hidratação do cimento, explicada pelos fenômenos que ocorreram nos estágios I e II desse processo [30].

Quando o cimento Portland reage com a água, os principais produtos formados são o silicato de cálcio hidratado (C-S-H), o hidróxido de cálcio ou portlandita $\left(\mathrm{Ca}(\mathrm{OH})_{2}\right)$, a etringita ( $\mathrm{C}_{6} \mathrm{~A} \overline{\mathrm{S}}_{3} \mathrm{H}_{32}=\mathrm{AFt}$ ) e o monossulfoaluminato de cálcio hidratado $\left(\mathrm{C}_{4} \mathrm{~A} \overline{\mathrm{S}} \mathrm{H}_{18}=\mathrm{AFm}\right)^{*}$. A velocidade de hidratação para cada composto do clínquer do cimento é distinta, sendo que a reatividade apresentada é, aproximadamente, a que se segue: $\mathrm{C}_{3} \mathrm{~A}>\mathrm{C}_{3} \mathrm{~S}>\mathrm{C}_{2} \mathrm{~S} \approx \mathrm{C}_{4} \mathrm{AF}^{*}$ [30]. Além disso, os aditivos superplastificantes não são adsorvidos uniformemente pelos componentes minerais do cimento: o $\mathrm{C}_{3} \mathrm{~A}$ e o $\mathrm{C}_{4} \mathrm{AF}$ adsorvem maiores quantidades de aditivo do que o $\mathrm{C}_{3} \mathrm{~S}$ e o $\mathrm{C}_{2} \mathrm{~S}[22,26,31]$. Assim, a fase aluminato e seus produtos de hidratação desempenham um papel importante no processo de hidratação inicial.

Inicialmente, a reação de hidratação ocorre rapidamente, formando uma camada fina de C-S-H sobre a superfí- cie do cimento, que age como uma barreira de difusão para a água, retardando a posterior hidratação. A membrana de C-S-H é permeável ao fluxo interno das moléculas de água e ao fluxo externo de íons $\left(\mathrm{Ca}^{2+} \mathrm{e} \mathrm{OH}^{-}\right)$da matriz. Assim, o excesso de íons $\mathrm{Ca}^{2+}$ gerado é expulso da fase sólida e difunde através da membrana de C-S-H para dentro da solução, reagindo para produzir $\mathrm{Ca}(\mathrm{OH})_{2}$. Porém, com o decorrer do tempo, um excesso de $\mathrm{Ca}(\mathrm{OH})_{2}$ precipita no fluido, enquanto um excesso de íons silicato é formado dentro da membrana. Esse processo intrínseco causa um diferencial de pressão osmótica, que rompe periodicamente a membrana e restaura a solução concentrada de silicato, permitindo o crescimento de C-S-H secundário durante o período de aceleração da hidratação. Como o C-S-H secundário possui carga negativa, os íons $\mathrm{Ca}^{2+}$, abundantes na solução de cimento, são atraídos e formam uma camada de cargas positivas adjacente à superfície do C-S-H recém-formado e os ânions do superplastificante se concentrarão preferencialmente ao redor da camada formada pelos íons $\mathrm{Ca}^{2+}$. Assim, é razoável considerar que os íons $\mathrm{Ca}^{2+}$ liberados pelo sistema não estarão disponíveis para as reações que levam à formação do $\mathrm{Ca}(\mathrm{OH})_{2}$, evitando que eles participem das reações de pega e endurecimento do materiais à base de cimento e, assim, inibindo ou retardando a hidratação. O menor grau de polimerização deve-se provavelmente à dispersão do C-S-H na presença do aditivo superplastificante e à redução da quantidade de água disponível para a reação de hidratação [13].

O processo de hidratação do cimento provavelmente será influenciado pela adsorção do aditivo, independentemente da maneira pela qual isso ocorre. A presença de moléculas orgânicas na interface sólido-líquido pode inibir a nucleação e o crescimento dos cristais. Durante a nucleação, a adsorção pode evitar que se obtenha núcleos com tamanhos críticos. Por outro lado, o crescimento dos produtos hidratados na presença de aditivos adsorvidos pode resultar na alteração estrutural pela intercalação e/ou mudanças na morfologia das partículas de hidratos [30].

Como observado por diversos pesquisadores, a interação entre um aditivo superplastificante e a etringitaé caracterizada pela amorfização dos primeiros cristais de etringita formados e por uma inibição de seu crescimento cristalino: os germes de etringita são mantidos, por um curto intervalo de tempo, em uma organização semelhante a um material amorfo e as moléculas de superplastificante são progressivamente adsorvidas na superfície desse material; os cristais normais de etringita começam a crescer novamente quando todas as moléculas de superplastificante já tiverem sido adsorvidas [18]. Além disso, a presença de superplastificante implica em uma modificação definitiva da morfologia da etringita: ao invés de serem em forma de agulha, os cristais formados são bem pequenos e aproximadamente cúbicos, o que pode contribuir com o mecanismo de fluidificação da mistura (Figs. 3 e 4).

\footnotetext{
* Abreviações empregadas na química do cimento: $\mathrm{C}=\mathrm{CaO} ; \mathrm{S}=\mathrm{SiO}_{2} ; \mathrm{A}=\mathrm{Al}_{2} \mathrm{O}_{3} ; \mathrm{F}=\mathrm{Fe}_{2} \mathrm{O}_{3} ; \overline{\mathrm{S}}=\mathrm{SO}_{3} ; \mathrm{H}=\mathrm{H}_{2} \mathrm{O}$.
} 


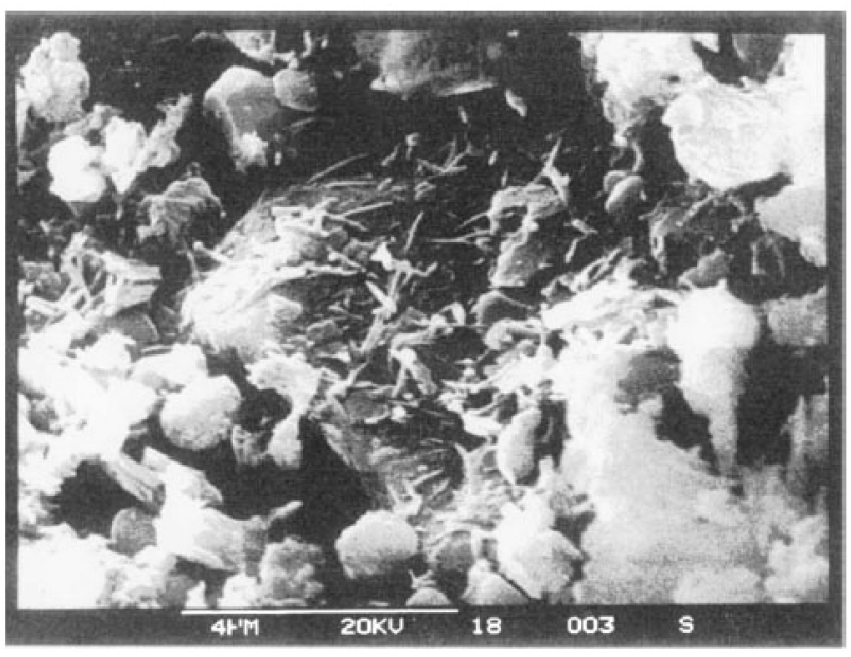

Figura 3: Imagem obtida por microscopia eletrônica de varredura de uma mistura sem superplastificante [18].

[Figure 3: SEM image of a mixture without superplasticizer [18].]

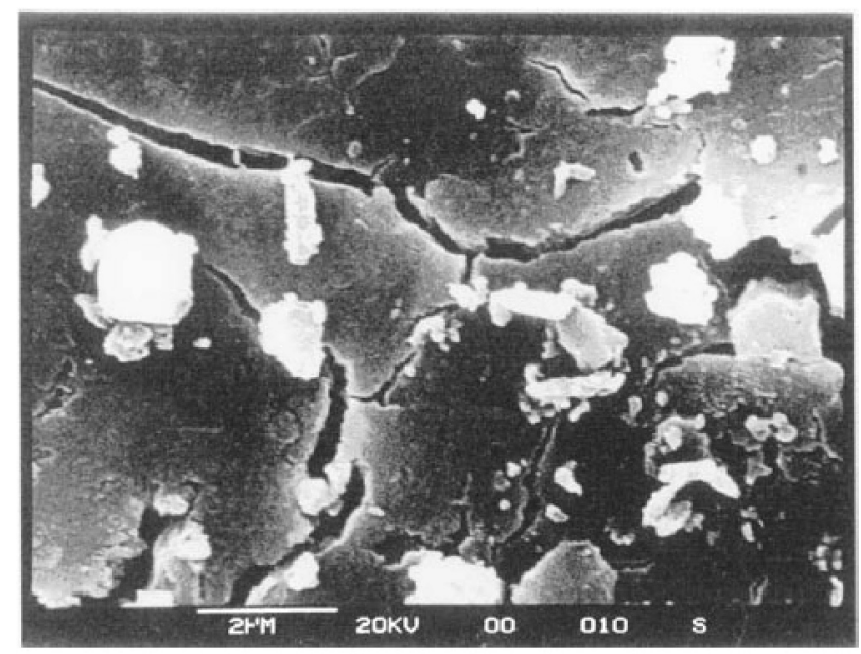

Figura 4: Imagem obtida por microscopia eletrônica de varredura de uma mistura contendo superplastificante à base de sulfonado de polinaftaleno [18].

[Figure 4: SEM image of a mixture containing a polynaphthalene sulfonate superplasticizer [18].]

As películas formadas pelas moléculas de aditivo ou pelos produtos da interação cimento-aditivo reduzem a taxa de hidratação, diminuindo a quantidade de água ligada ao cimento durante os primeiros instantes da hidratação e, assim, deixando uma maior quantidade de água livre, o que explica a maior fluidez de misturas à base de cimento na presença de aditivos. Assim, a adsorção das moléculas de superplastificante sobre as fases da hidratação tem duas conseqüências positivas: os germes carregados eletrostaticamente participam da repulsão eletrostática, evitando a aglomeração; e o crescimento das longas agulhas de etringita, que normalmente diminuem a capacidade de escoamento de uma mistura à base de cimento, é retardado [18].

Como o superplastificante interage com as reações químicas em andamento em uma mistura à base de cimento, uma fase organomineral pode ser formada em torno das partículas de cimento durante a hidratação do $\beta-\mathrm{C}_{2} \mathrm{~S}$, assim como pela precipitação da solução aquosa. A fase organomineral pode ser obtida com uma diversidade de polímeros (não-iônicos, aniônicos, catiônicos), demonstrando que sua formação ocorre quase que invariavelmente. A presença da fase organomineral pode influenciar o consumo de aditivo - o que pode ocorrer de formaimprodutiva-e,conseqüentemente, atrabalhabilidade da mistura [32]. Assim, a compreensão desses efeitos é de fundamental importância para a predeterminação de quais combinações de cimento e superplastificante resultarão ou não na melhores propriedades quando no estado fresco. Sendo assim, de uma maneira geral, o superplastificante adicionado às misturas à base de cimento pode ser dividido em três partes: parte é consumida pelas reações químicas, em particular durante a formação da etringita e do C$\mathrm{S}-\mathrm{H}$; parte é adsorvida sobre a superfície das partículas de cimento e não é integrada à fase organomineral na escala de tempo necessária para a aplicação do concreto; e parte corresponde ao superplastificante que permanece na fase aquosa, uma vez que polímero suficiente tenha sido adicionado para satisfazer o consumo de aditivo (o sistema pode ser considerado como saturado com superplastificante) [32].

Os efeitos dos diferentes tipos de superplastificantes existentes sobre a hidratação do cimento podem ser investigados pormeio de diversas técnicas de caracterização, as quais incluem: difração de raios X; medidas de condutividade elétrica; adsorção da solução; determinação do tamanho dos poros; medidas de viscosidade; calorimetria; medidas da resistência à compressão. Algumas das áreas chave que precisam ser examinadas são: química da hidratação do cimento; interface líquido/partícula de cimento; propriedades da superfície e da massa de concreto resultante do cimento; mudanças microestruturais na interface cimento/aditivo; propriedades da solução líquida presente nos poros; mudanças nas características da superfície; e solidificação/estabilização das substâncias tóxicas usando sistemas à base de cimento [13].

\section{Mecanismos de ação do superplastificante}

A produção de concretos de alto desempenho com baixa relação água/cimento necessita da utilização de aditivos superplastificantes para manter a fluidez adequada para a aplicação do material. A melhora na fluidez é conseguida principalmente por uma melhor dispersão das partículas sólidas por meio de forças de repulsão, embora outros mecanismos também possam contribuir: redução da tensão de superfície da água; repulsão eletrostática induzida entre as partículas; filme lubrificante entre as partículas de cimento; dispersão dos grãos de cimento, liberando a água aprisionada entre os aglomerados; inibição da reação de hidratação na superfície das partículas de cimento, deixando mais água livre para fluidificar a mistura; mudança na morfologia dos produtos de hidratação; impedimento estérico induzido evitando o contato partícula-partícula [4, 14, 15, 24]. 
As forças atuantes entre as partículas de cimento compreendem as forças de van der Waals (forças de atração) e as forças de repulsão eletrostática geradas pela carga elétrica presente na superfície das partículas. Porém, com a adição de um aditivo, as forças de repulsão eletrostática são aumentadas e, com isso, forças de repulsão estérica são geradas, realçando o aumento de densidade local causado pela sobreposição de camadas de aditivo adsorvido [6, 14]. Assim, a força atuante resultante entre as partículas de cimento em coexistência com um aditivo é representada pela somatória de todas as forças presentes, isto é, pela somatória das forças de atração de van der Waals e das forças de repulsão eletrostática e estérica. Além disso, a força atuante entre as partículas de cimento depende da distância entre elas, que por sua vez está relacionada com a energia de interação entre as partículas (Fig. 5).

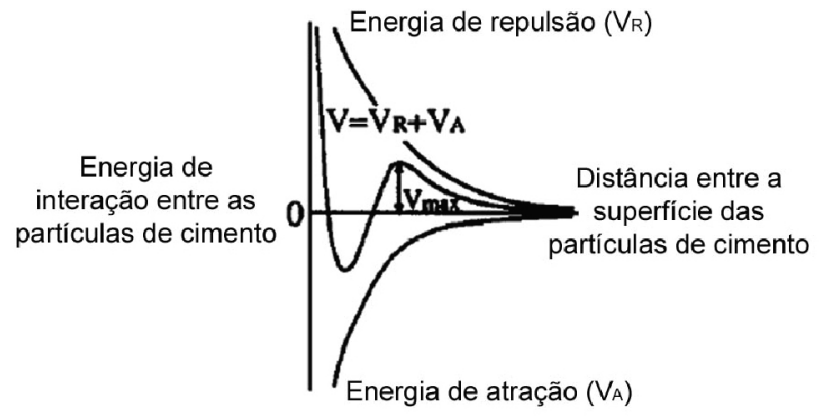

Figura 5: Relação entre a distância e a energia de interação entre as partículas de cimento [14].

[Figure 5: Relationship between distance and interactive energy among cement particles [14].]

Assim, vários tipos de forças coexistem em uma suspensão à base de cimento. Existem forças de origem coloidal que surgem a partir das interações mútuas entre as partículas e que são influenciadas pela polarização da água. Quando forças de atração são dominantes entre as partículas, o conjunto resulta na atração e as partículas tendem a aglomerar; porém, na presença de aditivos superplastificantes, o conjunto resulta na repulsão e as partículas permanecem separadas. Com relação a isto, as adições minerais podem influenciar as forças eletrostáticas dependendo de sua origem mineralógica e do estado das cargas da superfície de suas partículas. Como as forças coloidais também dependem da distância média entre as partículas vizinhas, a interposição de grãos desses materiais mais finos entre as partículas de cimento pode interferir na atração eletrostática e, conseqüentemente, na estrutura dos aglomerados. Igualmente, substituindo o cimento por um material com área específica diferente, muda-se a área superficial molhável e a quantidade de água adsorvida. Algumas adições, contendo uma determinada solubilidade em água, podem modificar a solução eletrolítica e, assim, as forças eletrostáticas [33].

São verificadas também forças viscosas que são proporcionais à diferença de velocidade de deslocamento entre as partículas de cimento e a água circundante, e entre um agregado e a pasta de cimento que o envolve. Como os materiais à base de cimento estão dentro da faixa de suspensões densas, as partículas têm que se afastar, especialmente quando aglomerados são formados. $\mathrm{O}$ efeito fíler sobre a reologia depende da distribuição granulométrica e da forma das partículas presentes. A viscosidade das suspensões geralmente aumenta à medida que se afasta da curva granulométrica ideal e atinge um mínimo para um determinado volume de água e para um arranjo de partículas mais compacto. Além do mais, qualquer divergência da forma esférica implica no aumento da viscosidade para um volume de pasta constante. Assim, na presença superplastificante, quanto mais fina e mais esférica for a adição mineral incorporada, melhores serão as propriedades reológicas da mistura. Esses materiais também podem apresentar diferentes eficiências para a adsorção do aditivo. Eles podem ser solúveis e introduzir íons que influenciam a cinética da reação de hidratação e a nucleação dos produtos hidratados [33].

Normalmente o termo estabilização eletroestérica é usado para descrever o mecanismo de dispersão imposto pelos aditivos superplastificantes (Fig. 6). A estabilização eletroestérica é uma combinação da repulsão eletrostática da dupla camada elétrica e da repulsão estérica, onde a variação e a magnitude de cada contribuição depende de diversos parâmetros, tais como a quantidade de aditivo adsorvido, o grau de dissociação do polieletrólito, a densidade do conjunto de cargas na superfície e a força iônica [12,34]. Se o aditivo se adsorve em uma conformação plana, a repulsão estérica é de curto alcance e o mecanismo de estabilização é principalmente eletrostático; para camadas de adsorção mais espessas, com cadeias de polímero projetando-se na solução, a contribuição estérica se tornará mais importante, porém existe sempre uma contribuição eletrostática, uma vez que a adsorção de um aditivo normalmente induz a um conjunto de cargas na superfície das partículas. As forças de repulsão eletrostática são determinadas medindo-se o potencial zeta de uma suspensão diluída de cimento, enquanto as forças

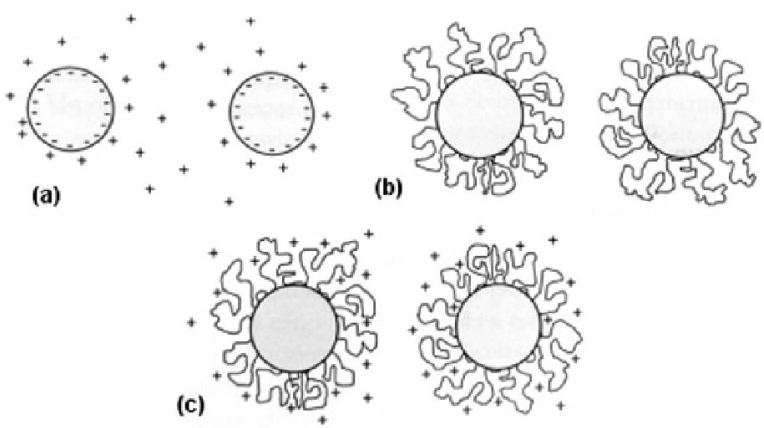

Figura 6: Ilustração dos mecanismos de estabilização de suspensões: (a) estabilização eletrostática, (b) estabilização estérica e (c) estabilização eletroestérica [5].

[Figure 6: Illustration of suspensions stabilization mechanisms: (a) electrostatic stabilization, (b) steric and (c) electrosteric one [5].] 
de repulsão estérica são calculadas subtraindo-se a força de repulsão eletrostática da força atuante entre as superfícies das partículas de cimento [14].

Para um sistema reativo, como o sistema cimentício, a química da superfície da fase sólida e a composição do eletrólito mudam com o tempo, criando uma situação bastante complexa: à medida que reação de hidratação ocorre, a quantidade de água livre diminui e, com isso, a distância entre as superfícies de hidratação das partículas de cimento vizinhas (hidratos); como o volume interpartículas se torna menor, a concentração de moléculas de superplastificante confinadas nesse volume pode criar um efeito substancial de pressão osmótica, que tende a expelir as moléculas de superplastificante do volume confinado entre as partículas, ou a criar um escoamento de água para diluir as moléculas de polímero naquela região; o primeiro caso resulta na indução da atração entre as partículas enquanto o segundo induz à repulsão adicional partícula-partícula [22].

O tempo de ação de um superplastificante é limitado pela reação entre o $\mathrm{C}_{3} \mathrm{~A}$, a água e o íon sulfato para a produção da etringita e pelo crescimento da camada de minerais hidratados na presença de aditivos. Assim, um aditivo superplastificante que pudesse ter um bom desempenho independentemente do método de adição, seria muito apreciado em uma usina de concreto ou em uma indústria de elementos pré-moldados de concreto, pois se reduziria a variabilidade do abatimento determinado para a mistura fresca ou da resistência do material no estado endurecido, ambos normalmente influenciados pela mudança no procedimento de adição do aditivo [15].

\section{EMPACOTAMENTO DE PARTÍCULAS}

Nos últimos anos, o interesse pelo empacotamento das partículas aumentou nas diferentes áreas da engenharia. Esse interesse pode ser explicado pelo fato de que uma grande parte dos materiais naturais ou industriais com os quais lidamos diariamente são - ou contém - partículas de diferentes formas e tamanhos. Nesse campo de ação, as "partículas" são consideradas como os grãos de agregados, minerais, metais ou pós químicos, solos, moléculas, poros ou rochas. Assim, o comportamento de tais materiais depende parcialmente das propriedades das partes que o compõem e parcialmente das interações entre elas [35].

A fluidez inicial de suspensões concentradas, tais como o concreto, também depende de considerações físicas, isto é, da distribuição granulométrica, do índice de forma e da textura superficial das partículas [24]. Sendo assim, o projeto da distribuição de tamanho de partículas é de fundamental importância, pois promove o empacotamento e, juntamente com o fluido, define as propriedades reológicas do material durante o processo de mistura e quando no estado fresco.

Atualmente, com a utilização de um superplastificante, os concretos de alto desempenho possuem uma maior densidade devido à redução na quantidade de água de mistura. Além disso, componentes finos e ultrafinos, com formato esférico - adições - têm sido adicionados às misturas tanto para facilitar o auto-adensamento quanto para garantir uma melhor compactação e preenchimento dos vazios existentes entre os grãos, aumentando ainda mais a densidade desses materiais [36].

Graças à utilização simultânea de aditivo superplastificante e de adições minerais tem sido possível produzir, em laboratório, concretos com resistência à compressão de aproximadamente $150 \mathrm{MPa}$ (medida em corpos-de-prova cilíndricos). Esses materiais, considerados de alto desempenho, podem interessar não apenas por causa da elevada resistência mecânica, mas também por outras características, tais como o maior módulo de elasticidade, menor exsudação, menor fluência e retração e maior durabilidade $[37,38]$. Resistências ainda maiores têm sido obtidas devido à utilização de técnicas especiais, como autoclave, compactação sob alta pressão ou impregnação com polímeros; porém, essas técnicas envolvem procedimentos caros e, que às vezes, são difíceis de serem aplicadas em elementos de escala real, como vigas e lajes.

Assim, o conceito de uma alta densidade de empacotamento foi recentemente redescoberto como um parâmetro chave para a obtenção de materiais cimentícios de ultra-alto desempenho.

\section{Modelos de empacotamento de partículas}

O estudo do empacotamento de partículas pode ser definido como o problema da correta seleção da proporção e do tamanho adequado dos materiais particulados, de forma que os vazios maiores sejam preenchidos por partículas menores, cujos vazios serão novamente preenchidos com partículas ainda menores e assim sucessivamente [5].

Em 1892 Féret publicou o primeiro tratado sobre o empacotamento de partículas em concreto, onde apresentou a possibilidade da seleção de tipos adequados de agregados e a relação entre a porosidade do material quando no estado endurecido e sua resistência à compressão, quando submetidos ao processo de cura normal (cura úmida). Segundo a equação apresentada, a resistência máxima é obtida quando a porosidade inicial da matriz é mínima, isto é, a densidade de empacotamento é máxima $[37,39,40]$. Desde então, alguns modelos de empacotamento têm sido propostos como ferramentas para calcular a densidade de empacotamento das partículas e, assim, otimizar misturas granulares de concretos.

Os estudos teóricos e experimentais relacionados ao empacotamento de partículas resultaram de duas abordagens básicas: uma discreta, que considera as partículas individualmente (modelo de Furnas, equação A); e outra contínua, que trata as partículas como distribuições contínuas (modelo de Andreasen, equação B).

$$
\operatorname{CPFT}(\%)=100\left(\frac{D^{\log r}-D_{S}^{\log r}}{D_{L}^{\log r}-D_{S}^{\log r}}\right)
$$




$$
\operatorname{CPFT}(\%)=100\left(\frac{\mathrm{D}}{\mathrm{D}_{\mathrm{L}}}\right)^{\mathrm{q}}
$$

onde CPFT é a porcentagem volumétrica de partículas menores que o diâmetro $\mathrm{D}, D_{L}$ é o diâmetro da maior partícula, $D_{S}$ é o diâmetro da menor partícula, $r$ é a razão entre o volume de partículas entre duas malhas de peneiras consecutivas e $q$ é o módulo ou coeficiente de distribuição.

Recentemente, após uma extensa análise comparativa entre os modelos de Furnas e Andreasen, algumas considerações foram feitas, ficando provado que ambos os modelos convergem matematicamente para uma mesma equação (equação C). Normalmente conhecida como modelo de Alfred, esta é um aperfeiçoamento dos modelos anteriores e mostra que, na realidade, os modelos de Furnas e de Andreasen podem ser visualizados como duas formas distintas de se expressar a mesma coisa. Além de introduzir o conceito do tamanho mínimo de partículas $\left(D_{S}\right)$ na equação de Andreasen, envolve também uma revisão matemática do modelo de Furnas [5].

$$
\operatorname{CPFT}(\%)=100\left(\frac{D^{q}-D_{S}^{q}}{D_{L}{ }^{q}-D_{S}^{q}}\right)
$$

Por meio de simulações computacionais foi verificado que valores de $q$ menores ou iguais a 0,37 podem favorecer o empacotamento máximo para distribuições infinitas, enquanto que para valores acima de 0,37 , verifica-se sempre uma porosidade residual. Para uma mistura apresentar boa capacidade de escoamento, o valor do coeficiente de distribuição deve ser menor que 0,30 ; assim, a consideração de $q$ com valores próximos a 0,30 favorece a produção de concretos adensados sob vibração, enquanto que valores menores que 0,25 resulta em misturas auto-adensáveis [41]. $\mathrm{O}$ efeito da redução do valor do coeficiente de distribuição se dá no aumento da quantidade de finos, que influencia a interação entre as partículas.

Existem diferenças consideráveis entre os modelos apresentados anteriormente. Comparando-se as densidades obtidas experimentalmente a partir desses modelos, a eficiência de empacotamento resultante das diversas distribuições de máxima densidade é dada conforme a seqüência: Alfred $>$ Andreasen $>$ Furnas [5].

Para o desenvolvimento dos concretos de alta resistência e de alto desempenho, as características de empacotamento das partículas são de fundamental importância. Esses concretos são considerados, de fato, materiais com alta densidade de empacotamento e a idéia por trás desse conceito é a tentativa de reconstrução de uma rocha sólida a partir de elementos que possuem granulometrias complementares [42].

Ao estudar o comportamento dos concretos depara-se com um problema relacionado com a garantia de se reproduzir materiais com uma distribuição granulométrica precisa. Considerações sobre esse problema devem-se ao fato das matérias-primas possuírem distribuições granulométricas contínuas, nem sempre reprodutíveis ao longo do tempo.

Uma simples análise convencional dos teores de cimento e de agregados miúdo e graúdo não é suficiente para tornar reprodutíveis os concretos produzidos com as diversas matérias-primas existentes. A sistematização do processo de dosagem exige um maior rigor na técnica de combinação das matérias-primas para que a mistura das mesmas represente efetivamente a distribuição estudada teoricamente [43].

As leis que determinam o empacotamento de partículas esféricas já são conhecidas há muito tempo, porém, a forma das partículas dos materiais granulares comumente encontrados nos concretos está distante de uma esfera e deve-se admitir que, tradicionalmente na tecnologia dos concretos, pouca atenção é dada à busca de uma distribuição granulométrica ótima das partículas [7]. Em algumas situações, o problema da distribuição descontínua foi parcialmente superado com a incorporação de adições minerais (constituídas de partículas esféricas) ao cimento.

\section{Fatores que influenciam o empacotamento de partículas}

De uma forma geral, o empacotamento aleatório de monodispersões esféricas resulta sempre em um mesmo fator de empacotamento $(\approx 0,60-0,64)$, porém uma série de fatores pode alterar o empacotamento de um determinado conjunto de partículas.

O primeiro a ser considerado é a existência de partículas com distribuições granulométricas diversas alterando a condição de dispersão inicial. Com isso, podem-se obter sistemas com fatores de empacotamento elevados - próximos de 1 - até misturas onde esse fator se aproxima do nível das monodispersões [5].

$\mathrm{O}$ outro fator que pode alterar a condição de empacotamento é a morfologia das partículas. Quanto menos esférica for a partícula, menor será a densidade de empacotamento de uma distribuição que a contenha, pois se verifica o atrito entre as partículas a partir do contato de suas superfícies irregulares. Quanto menor o tamanho das partículas irregulares, maior será esse efeito, devido à maior área superficial específica [5].

A porosidade interna das partículas também altera a densidade de um material. As partículas podem ser totalmente densas, com porosidade interna fechada ou com porosidade aberta. Para se obter um empacotamento com densidade máxima, considerando uma determinada distribuição granulométrica, é necessário que se utilizem partículas não porosas; porém essas partículas não são as mais usuais. Para efeito de distribuição granulométrica, as partículas que apresentam porosidade fechada são semelhantes às densas, porém resultam em misturas com densidade superior. Já as partículas que apresentam porosidade aberta perturbam o empacotamento devido ao seu formato irregular e também resultam em misturas com menores densidades de empacotamento [5].

Empacotamentos com menor porosidade podem ser obtidos se os vazios existentes entre as partículas de uma dispersão forem preenchidos por partículas menores que os 
mesmos. Porém, caso sejam introduzidas partículas maiores que os vazios existentes, essas promoverão o surgimento de novos vazios, levando a um aumento na porosidade e redução da eficiência do empacotamento. Assim, a seqüência de preenchimento dos vazios existentes entre as partículas, ou melhor, a distribuição granulométrica do sistema determina o aumento ou não da densidade de empacotamento da monodispersão [5].

Aproximadamente metade das partículas de adições minerais e dos cimentos tem formato próximo ao de uma esfera, porém a porção relativa dessas partículas diminui durante o curso da hidratação de suspensões à base de cimento em decorrência da formação de partículas com forma irregular, o que é mais evidente em misturas contendo sílica ativa. Assim, as primeiras horas da hidratação de suspensões à base de cimento são caracterizadas por variações no diâmetro efetivo e na distribuição granulométrica das partículas. Diversos fatores contribuintes acontecem simultaneamente: por um lado, a dissolução das partículas de cimento e a diminuição do seu diâmetro efetivo; e, por outro lado, a aglomeração das partículas pequenas [44].

Analisando a influência da distribuição granulométrica sobre a densidade de empacotamento e o grau de hidratação de um sistema à base de cimento verifica-se que uma distribuição contínua de partículas é muito procurada para o estado de empacotamento, enquanto uma distribuição heterogênea é mais adequada para a taxa de hidratação. Assim, os dois efeitos são exatamente opostos; porém, para as propriedades dos materiais, eles devem ser considerados simultaneamente: por um lado, uma maior densidade de empacotamento é necessária, enquanto que, por outro lado, um maior grau de hidratação é desejável. Resumidamente, o material deve ter a menor porosidade possível [39]. Além disso, a dosagem de uma mistura depende da densidade de empacotamento: a menor porosidade é coincidente com a máxima densidade de empacotamento, onde o grau de hidratação é geralmente menor, definindo a dosagem ótima para uma mistura. Isso mostra que o efeito da densidade de empacotamento é o fator mais importante [39].
A distribuição granulométrica também pode influenciar na demanda de água necessária para produzir uma mistura com trabalhabilidade adequada aos processos de aplicação e adensamento. A demanda de água da mistura está relacionada com a área superficial e com densidade de empacotamento das partículas: quanto maior a área superficial e menor a densidade de empacotamento, maior a demanda de água. Assim, mantendo-se a área superficial constante, quanto mais estreita for a distribuição granulométrica das partículas, maior será a demanda de água para se obter uma mistura com trabalhabilidade adequada [40].

Quando a relação água/cimento é mantida constante, a área superficial aumenta com o aumento da densidade de empacotamento. Em outras palavras, pode-se dizer que a área superficial pode aumentar sem acréscimo da demanda de água por meio de ajuste na distribuição granulométrica das partículas. Porém, deve-se observar que esse efeito é muito limitado: como a densidade de empacotamento é menor que 1, deduz-se que a área superficial máxima seja igual a razão entre a relação água/cimento e espessura do filme d'água ao redor das partículas; quando a área superficial for maior que a área superficial máxima, o aumento desse parâmetro sempre será acompanhado de um aumento na demanda de água [40].

Além dos fatores relacionados com as características do sistema de partículas - distribuição granulométrica, morfologia, porosidade - a forma como essas partículas são colocadas em suas posições de equilíbrio deve ser considerada quando se deseja obter empacotamento máximo. No empacotamento de camadas sucessivas, cada camada monodispersa possui o mesmo fator de empacotamento e a mistura de diversos diâmetros não contribui para $o$ preenchimento dos vazios existentes entre as partículas, resultando em um empacotamento global semelhante ao de uma monodispersão; porém, quando as partículas menores ocupam os interstícios entre as partículas maiores, o empacotamento é otimizado, diminuindo a porosidade do sistema. Assim, uma mesma distribuição granulométrica pode gerar empacotamentos distintos dependendo da técnica

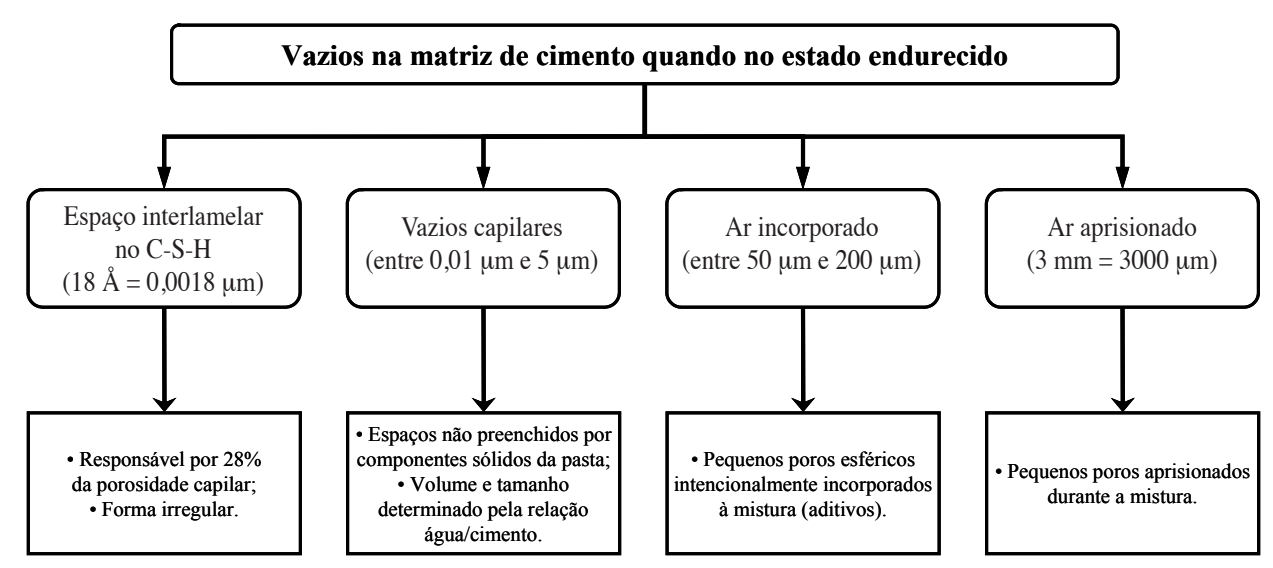

Figura 7: Vazios presentes na matriz de cimento quando no estado endurecido [46].

[Figure 7: Voids origin in hardened cement matrix [46].] 
de compactação adotada $[5,45]$.

O estado de dispersão das partículas também deve ser considerado quando se busca um empacotamento máximo. A dispersão inadequada de partículas (formação de aglomerados) pode alterar a curva de distribuição granulométrica inicialmente prevista, aumentando o diâmetro mínimo efetivo da composição e, assim, reduzindo a densidade de empacotamento. Além disso, os aglomerados formados equivalem a partículas vazias que originam poros na microestrutura, prejudicando o desempenho mecânico do produto gerado [5].

\section{Porosidade}

Em um concreto de cimento Portland, poros existem dentro dos próprios agregados, na interface pasta/agregado e na pasta de cimento. É por meio desses vazios que os agentes agressivos (gases, líquidos e sólidos dissolvidos) se movem através da pasta de cimento endurecida; conseqüentemente, a porosidade funciona como uma ponte que liga a distribuição granulométrica e as propriedades do material. Assim, a porosidade e a estrutura de poros da pasta de cimento (Fig. 7) são de grande importância para o desempenho de compósitos à base de cimento quando no estado endurecido, influenciando todas as suas propriedades $[17,40,46]$.

A melhoria da estrutura de poros de um concreto de alto desempenho é alcançada pelo uso simultâneo de aditivos químicos e adições minerais. Os aditivos permitem uma redução substancial da água de mistura e, assim, o tamanho dos poros e a quantidade de ar aprisionado são reduzidos, criando-se uma microestrutura mais densa quando no estado endurecido. Já as adições minerais fornecem uma redução adicional da porosidade da matriz e melhoram a interface com os agregados [47].

Os poros capilares em uma matriz de cimento pura hidratada são determinados principalmente pela relação água/cimento. Assim, uma relação água/cimento baixa é obrigatória para a criação de materiais à base de cimento com porosidade e permeabilidade reduzidas. Se a relação água/cimento inicial for relativamente menor do que 0,38 - valor mínimo para o qual o cimento pode ser completamente hidratado - uma parte das partículas de aglomerantes permanece não-hidratada na pasta madura, sendo consideradas como fílers internos. A presença dessas partículas em compósitos com baixa porosidade pode influenciar a estabilidade termodinâmica ou a durabilidade do material [48].

Para analisar a influência da distribuição granulométrica sobre as propriedades de um material à base de cimento no estado endurecido, a densidade de empacotamento e o grau de hidratação são dois fatores que influenciam indiretamente tais propriedades, sendo a relação direta estabelecida apenas por meio da porosidade. Sabe-se que as propriedades dos materiais à base de cimento estão intimamente relacionadas com sua porosidade que, por sua vez, depende da densidade de empacotamento das partículas de cimento e do seu grau de hidratação. Maiores densidades de empacotamento resultam em menores porosidades, assim como um maior grau de hidratação do cimento. Porém, a influência da distribuição granulométrica sobre a densidade de empacotamento e sobre o grau de hidratação é inconsistente: para uma distribuição granulométrica mais ampla, a densidade de empacotamento é maior, enquanto o grau de hidratação é menor; para uma distribuição granulométrica mais estreita, a densidade de empacotamento é menor, enquanto o grau de hidratação é maior [39].

Assim, dois aspectos devem ser considerados simultaneamente e seus efeitos completos devem ser observados. Quando o grau de hidratação é pequeno (primeiras idades), a influência da densidade de empacotamento é principal, enquanto o efeito do grau de hidratação é secundário. Quando o grau de hidratação é maior (idades mais avançadas), tanto a densidade de empacotamento quanto o grau de hidratação influenciam a porosidade simultaneamente: o sistema não possui apenas uma maior densidade de empacotamento, mas também um maior grau de hidratação, resultando em uma menor porosidade. Assim, do ponto de vista da porosidade, as influências da densidade de empacotamento e do grau de hidratação devem ser consideradas cooperativamente, indicando que uma distribuição granulométrica mais ampla é mais vantajosa para se obter uma mistura com uma menor porosidade [40].

O processo de hidratação do cimento também caracteriza a área superficial de produtos hidratados desenvolvidos e são esses produtos que criam a estrutura de poros quando no estado endurecido. Existe uma dependência entre a área superficial dos produtos da hidratação e a área superficial e o volume de poros. Assim, a razão entre o volume acumulado e a área superficial de poros pode indicar a atividade de hidratação de um material à base de cimento [48].

Um outro fator que influencia a qualidade dos concretosé o processo de cura adotado [47]. A porosidade total - incluindo o espaço capilar - de uma matriz de cimento diminui com o aumento do tempo de cura, uma conseqüência esperada devido ao preenchimento do espaço entre as partículas com os novos produtos da hidratação. Em materiais à base de cimento incorporados com sílica ativa, o aumento do tempo de cura fornece uma maior probabilidade de formação de uma porosidade descontínua, com uma maior proporção de capilares menores em sua estrutura. Além disso, o diâmetro médio dos poros muda em função do tempo de cura, o que pode estar relacionado com a restrição da mobilidade da água de pastas com diferentes composições [48].

\section{Adições minerais}

A utilização de adições minerais em complemento ou substituição parcial ao cimento para a produção de concretos com propriedades e características melhoradas tem aumentado nos últimos anos. Fatores econômicos e ambientais têm um papel importante no crescimento do uso desses materiais. Eles fornecem um conforto ambiental, pois subprodutos industriais são reciclados, emissões perigosas 
lançadas na atmosfera durante a produção do cimento são reduzidas, matérias-primas são preservadas e energia é economizada [33, 49]. Assim, existe um duplo benefício ambiental por meio da utilização das adições minerais, resultando em concretos ecologicamente corretos.

Uma das maneiras de se produzir um concreto com alta durabilidade é pela incorporação de adições minerais - tais como a sílica ativa, a cinza volante, a escória de alto forno, a cinza e/ou a sílica da casca de arroz, etc. - na composição de um concreto. Além de modificar as propriedades físicas e mecânicas do concreto quando usadas como material cimentício suplementar, essas adições preenchem a porosidade do esqueleto granular do concreto, melhorando a ação ligante do cimento e resultando em uma menor porosidade do concreto quando no estado endurecido (microestrutura mais densa), o que reduz a permeabilidade e aumenta a durabilidade do material frente à ação de agentes agressivos, tais como os íons sulfato e cloreto e água do mar [50].

As adições minerais são diferentes do cimento Portland em três aspectos principais: elas possuem uma menor densidade específica, suas partículas são menores e apresentam uma atividade pozolânica [51].Assim, as adições minerais, normalmente pozolanas, são definidas como materiais inorgânicos finamente moídos, adicionados em quantidades significativas para melhorar certas propriedades ou para alcançar propriedades especiais no concreto [52]. Uma definição mais formal descreve a pozolana como um material silicoso ou sílico-aluminoso que, por si só, tem pouco ou nenhum valor cimentício, mas quando finamente moído e na presença de umidade, reage quimicamente com o hidróxido de cálcio (resultante da hidratação do cimento) à temperatura ambiente formando silicatos estáveis com propriedades cimentícias, processo conhecido como reação pozolânica [25].

Quando a sílica ativa reage com o hidróxido de cálcio, existe um aumento do calor de hidratação particularmente nos primeiros instantes, o que não é observado quando a cinza volante ou qualquer outro material cimentício suplementar de baixa reatividade são incorporados à mistura. Assim, verifica-se que a taxa da reação pozolânica é dependente de vários fatores, tais como a origem, as composições química e mineralógica, a morfologia e a granulometria da adição mineral [53].

Nasprimeirasidades, aadiçãomineralpodeserconsiderada um inerte, um material fino, mas não um aglomerante, uma vez que suas reações químicas não ocorrem na mesma taxa que as reações de hidratação do cimento. Porém, a situação é complexa devido ao efeito físico provocado pela adição mineral sobre o empacotamento de partículas e, dessa maneira, sobre as forças que controlam a distância entre as partículas de cimento no início do processo de hidratação [54]. O efeito físico conhecido como efeito fíler corresponde ao processo de refinamento dos poros associado à reação pozolânica: os produtos da reação de hidratação são bastante eficientes no preenchimento dos espaços capilares grandes, aumentando a resistência e reduzindo a permeabilidade do sistema [46].
As adições minerais modificam a cinética da hidratação do cimento, especialmente nas primeiras idades. Na maioria dos casos, os resultados são apresentados como variações do grau de hidratação, da quantidade de água ligada e da evolução do calor de hidratação total entre as misturas com e sem a incorporação de adição mineral. Normalmente três efeitos físicos principais são observados sobre a hidratação do cimento quando adições minerais estão presentes na composição de materiais à base de cimento: a) o efeito de diluição do cimento, equivalente ao aumento da relação água/cimento, é inversamente proporcional à taxa de substituição; b) o efeito da distribuição granulométrica, que depende da granulometria e da quantidade de adição mineral usada e está relacionado com a modificação da porosidade inicial da mistura; e c) a nucleação heterogênea, processo físico conduzido pela ativação química da hidratação do cimento que catalisa o processo de nucleação dos hidratos por meio da redução da barreira de energia. A diluição do cimento e a modificação da distribuição granulométrica são conseqüências diretas da substituição do cimento por uma adição mineral, enquanto a nucleação heterogênea se torna significativa para adições minerais mais finas [55].

Dessa maneira, a propriedade física principal das adições minerais é sua área superficial específica, que junto com uma função eficiência, pode ser usada para descrever o aumento do grau de hidratação ou da resistência à compressão de materiais à base de cimento decorrente dos efeitos físicos e químicos das adições minerais presentes.

As adições minerais incorporadas a uma mistura de concreto podem ser classificadas em três categorias morfológicas de acordo com sua forma: esférica, lamelar e irregular. A demanda de água das partículas de forma esférica e lamelar apresenta uma forte correlação com a área superficial específica; porém, o mesmo não é verdade para as partículas de forma irregular.

$\mathrm{Na}$ matriz de cimento, a água pode ser dividida em duas partes: água de preenchimento dos vazios entre as partículas; e água da camada de superfície, que forma um filme d'água sobre a superfície das partículas, influenciando diretamente a fluidez da mistura. A quantidade de água de preenchimento está relacionada com a densidade de empacotamento do sistema de partículas, enquanto a quantidade de água na camada de superfície está relacionada com a área específica desse sistema.

A adição de material pozolânico influencia a densidade de empacotamento do sistema, alterando, assim, a quantidade de água de preenchimento; como o material pozolânico possui uma área superficial específica maior do que o cimento, ele também influencia a quantidade de água na camada de superfície. Assim, se a área superficial específica do material pozolânico não for muito elevada, sua adição diminui a quantidade de água de preenchimento, mas aumenta a quantidade de água na camada de superfície; em geral, neste caso, a quantidade total de água não é alterada. Por outro lado, se a área específica do material pozolânico for muito elevada, a quantidade total de água é aumentada devido ao aumento significativo da demanda de água na camada de superfície, mesmo a quantidade de água de 
preenchimento sendo reduzida [51].

Sabe-se que o superplastificante pode reduzir a demanda de água; mais especificamente, ele pode diminuir apenas a quantidade de água na camada de superfície, mas não a quantidade de água de preenchimento. Assim, o efeito do superplastificante é limitado, ou seja, existe uma redução máxima da quantidade de água [51]. Para a pasta de cimento pura, a redução máxima é baixa, porque a quantidade de água na camada de superfície é menor. Para um sistema binário (cimento mais material pozolânico), os limites máximo e mínimo possíveis para a relação água/cimento estão relacionados com a área específica e o teor de material pozolânico, respectivamente.

De uma maneira geral, a demanda de água para um material à base de cimento pode ser bastante reduzida quando um material pozolânico é adicionado junto com um aditivo superplastificante; porém a porcentagem ótima para a substituição do cimento por uma adição mineral não é constante para todas as relações água/cimento, sendo dependente do teor de água da mistura [56].

Além da relação água/cimento, do tipo e das características (composição) do cimento, da temperatura inicial e de cura, dos teores de álcalis solúveis e de aditivos químicos, a dosagem, a natureza e o tipo de adição mineral podem influenciar as características de pega do concreto. $\mathrm{O}$ efeito geral das diferentes adições minerais é aumentar os tempos de pega, o que depende do início e da taxa da reação pozolânica. Dessa maneira, os tempos de pega são considerados resultados de duas etapas fundamentais: a coagulação que estabelece contato entre as partículas e a formação de hidratos na zona de interface, tornando rígida a estrutura coagulada [57].

Dentre as variáveis que mais influenciam o desenvolvimento da resistência do concreto estão a relação água/cimento, a quantidade total de material cimentício e a razão cimento/aditivo. Os métodos de adição ou substituição não são suficientes para estimar corretamente a contribuição do material pozolânico sobre as propriedades do concreto. Sendo assim, sua atividade é normalmente avaliada em termos da quantidade de cimento substituída, denominada como fator de eficiência cimentante [56].

A adição de um material pozolânico influencia a demanda de água de mistura de um sistema e, conseqüentemente, sua resistência. Para uma mesma consistência, a incorporação de adição mineral aumenta consideravelmente a demanda de água e, assim, reduz a resistência do sistema (particularmente aos 7 dias de idade); porém, com a adição simultânea de um superplastificante, seu efeito fíler será completo e a resistência aumentará significativamente [51]. Além disso, a incorporação de adição mineral pode acelerar o processo de hidratação do cimento, sendo possível verificar resistências à compressão praticamente iguais em materiais à base de cimento com idades avançadas (entre 28 e 90 dias de idade) [58]. Assim, com a incorporação conjunta do material pozolânico e do aditivo superplastificante, o efeito fíler do material pozolânico será evidente e significativo.

De uma maneira geral, o efeito da incorporação das adições minerais sobre as propriedades do concreto no estado fresco depende principalmente da forma de suas partículas e de sua distribuição granulométrica. Sobre as propriedades do concreto no estado endurecido, seu efeito depende do comportamento da mistura quando no estado fresco e também das propriedades químicas que interferem no desenvolvimento da resistência e da durabilidade.

Com a introdução de adições minerais nas misturas de concreto, as propriedades mecânicas e a trabalhabilidade dos mesmos são melhoradas, enquanto a permeabilidade e a porosidade capilar são reduzidas. Com o refinamento dos poros, a zona de interface entre o agregado e a matriz é drasticamente reduzida e a exsudação interna e superficial da mistura é minimizada. Tudo isso leva a um alto desempenho do concreto com conseqüente aumento de sua durabilidade.

\section{TENDÊNCIAS}

Apesar da existência de algumas barreiras, ao longo dos anos, algumas inovações foram feitas na tecnologia dos materiais à base de cimento. As mais significativas delas incluem os concretos de alto desempenho e os concretos auto-adensáveis. Porém, a sustentabilidade e a produtividade são os parâmetros chave para que novas inovações ainda sejam efetuadas no campo desses materiais [59].

Os concretos modernos têm sido desenvolvidos para a obtenção de materiais com desempenhos mecânicos e de durabilidade cada vez maiores. Para tanto, concretos obtidos a partir do conhecimento e de técnicas empregadas na área de engenharia de microestrutura de materiais são necessários. Por meio das ferramentas experimentais e teóricas atualmente disponíveis é possível compreender as relações entre as propriedades macroscópicas desses materiais e os processos químicos e físicos que ocorrem dentro dos mesmos tanto em escala microscópica quanto em escala nanométrica [59].

Por serem compósitos constituídos de partículas com granulometria fina e uma baixa relação água/cimento, esses concretos apresentam matrizes densas obtidas a partir da otimização do empacotamento dos materiais granulares, enquanto a trabalhabilidade adequada é obtida com a dispersão das partículas promovida pela incorporação de aditivos químicos. Além disso, utilizam adições minerais que são, na grande maioria, subprodutos industriais, resultando em um grande benefício ambiental.

Apesar de serem utilizados em aplicações especiais, os conceitos de empacotamento e dispersão de partículas são pouco conhecidos pela maioria dos arquitetos e engenheiros atuantes na construção civil, especialmente no Brasil. Assim, os conhecimentos de empacotamento e dispersão aplicados aos concretos destinados à construção civil resultam em um novo processo de dosagem baseado em conceitos mais fundamentais, constituindo uma alternativa bastante eficiente aos métodos existentes.

\section{AGRADECIMENTOS}

Ao CNPq - Conselho Nacional de Desenvolvimento 
Científico e Tecnológico pela bolsa de estudo concedida e às empresas Holcim Brasil S.A., Elkem Materials South America Ltda., Basf Construction Chemicals Brasil e Mineração Jundu Ltda., pela doação dos materiais utilizados na pesquisa.

\section{REFERÊNCIAS}

[1] P.-C. Aïtcin, Cements of yesterday and today; concrete of tomorrow, Cem. Concr. Res. 30, 9 (2000) 1349-1359.

[2] P. Richard, M. Cheyrezy, Composition of reactive powder concretes, Cem. Concr. Res. 25, 7 (1995) 1501-1511.

[3] F. de Larrard, Ultrafine particles for the making of very high strength concretes, Cem. Concr. Res. 19, 2 (1989) 161172.

[4] P.-C. Aïtcin, C. Jolicoeur, J. G. MacGregor, Superplasticizers: how they work and why they occasionally don't, Concrete Int. 16, 5 (1994) 45-52.

[5] I. R. de Oliveira, A. R. Studart, R. G. Pileggi, V. C. Pandolfelli, Dispersão e empacotamento de partículas - princípios e aplicações em processamento cerâmico, Fazendo Arte Editorial, S. Paulo, SP (2000).

[6] R. J. Flatt, P. Bowen, Electrostatic repulsion between particles in cement suspensions: domain of validity of linearized Poisson-Boltzmann equation for nonideal electrolytes, Cem. Concr. Res. 33, 6 (2003) 781-791.

[7] P.-C. Aïtcin, Concreto de alto desempenho, PINI, S. Paulo (2000).

[8] Associação Brasileira de Normas Técnicas, NBR 11768: aditivos para concreto de cimento Portland, Rio de Janeiro (1992).

[9] American Society for Testing and Materials, ASTM C 494: standard specification for chemical admixtures for concrete, Book of Standards Volume 04.02 (1992).

[10] K. Yamada, T. Takahashi, S. Hanehara, M. Matsuhisa, Effects of the chemical structure on the properties of polycarboxylate-type superplasticizer, Cem. Concr. Res. 30, 2 (2000) 197-207.

[11] T. M. Vickers Jr., S. A. Farrington, J. R. Bury, L. E. Brower, Influence of dispersant structure and mixing speed on concrete slump retention, Cem. Concr. Res. 35, 10 (2005) 1882-1890.

[12] A. Kauppi, K. M. Andersson, L. Bergström, Probing the effect of superplasticizer adsorption on the surface forces using the colloidal probe AFM technique, Cem. Concr. Res. 35, 1 (2005) 133-140.

[13] M. Yousuf,A. Mollah,P.Palta,T.R.Hess, R. K. Vempati, D. L. Cocke, Chemical and physical effects of sodium lignosulfonate superplasticizer in the hydration of Portland cement and solidification/stabilization consequences, Cem. Concr. Res. 25, 3 (1995) 671-682.

[14] H. Uchikawa, S. Hanehara, D. Sawaki, The role of steric repulsive force in the dispersion of cement particles in fresh paste prepared with organic admixture, Cem. Concr. Res. 27, 1 (1997) 37-50.

[15] M. Collepardi, Admixtures used to enhance placing characteristics of concrete, Cem. Concr. Comp. 20, 2-3
(1998) 103-112.

[16] S. Erdogdu, Compatibility of superplasticizers with cements different in composition, Cem. Concr. Res. 30, 5 (2000) 767-773.

[17] K.C. Hover, Concrete mixture proportioning with waterreducing admixtures to enhance durability: a quantitative model, Cem. Concr. Comp. 20, 2-3 (1998) 113-119.

[18] W. Prince, M. Edwards-Lajnef, P.-C. Aïtcin, Interaction between ettringite and a polynaphthalene sulfonate superplasticizer in a cementitious paste, Cem. Concr. Res. 32, 1 (2002) 79-85.

[19] S. Jiang, B.-G.Kim, P.-C.Aïtcin, Importance of adequate soluble alkali content to ensure cement/superplasticizer compatibility, Cem. Concr. Res. 29, 1 (1999) 71-78.

[20] I. Masood, S. K. Agarwal, Effect of various superplasticizers on rheological properties of cement paste and mortars, Cem. Concr. Res. 24, 2 (1994) 291-302.

[21] Y. Nakajima, K. Yamada, The effect of the kind of calcium sulfate in cements on the dispersing ability of poly $\beta$-naphthalene sulfonate condensate superplasticizer, Cem. Concr. Res. 34, 5 (2004) 839-844.

[22] S. Chandra, J. Björnström, Influence of cement and superplasticizer type and dosage on the fluidity of cement mortars - part I, Cem. Concr. Res. 32, 10 (2002) 16051611.

[23] S. Chandra, J. Björnström, Influence of cement and superplasticizer type and dosage on the slump loss of Portland cement mortars - part II, Cem. Concr. Res. 32, 10 (2002) 1613-1619.

[24] D. Bonen, S. L. Sarkar, The superplasticizer adsorption capacity of cement pastes, pore solution composition, and parameters affecting flow loss, Cem. Concr. Res. 25, 7 (1995) 1423-1434.

[25] A. M. Neville, Propriedades do concreto, $2^{\mathrm{a}}$ Ed., PINI, S. Paulo (1997).

[26] S. Hanehara, K. Yamada, Interaction between cement and chemical admixture from the point of cement hydration, absorption behavior of admixture, and paste rheology, Cem. Concr. Res. 29, 8 (1999) 1159-1165.

[27] L. Agulló, B. Toralles-Carbonari, R. Gettu, A. Aguado, Fluidity of cement pastes with mineral admixtures and superplasticizer - a study based on the Marsh cone test, Mater. Struct. 32, 221 (1999) 479-485.

[28] F. de Larrard, F. Bosc, C. Catherine, F. Deflorenne, The AFREM method for the mix-design of high performance concrete, Mater. Struc. 30, 7 (1997) 439-446.

[29] F. Kreppelt, M. Weibel, D.Zampini, M.Romer,Influence of solution chemistry on the hydration of polished clinker surfaces - a study of different types of polycarboxylic acidbased admixtures, Cem. Concr. Res. 32, 2 (2002) 187-198.

[30] C. Jolicoeur, M.-A. Simard, Chemical admixturecement interactions: phenomenology and physico-chemical concepts, Cem. Concr. Comp. 20, 2-3 (1998) 87-101.

[31] K. Yoshioka, E.-I. Tazawa, K. Kawai, T. Enohata, Adsorption characteristics of superplasticizers on cement component minerals, Cem. Concr. Res. 32, 10 (2002) 1507 1513 . 
[32] R. J. Flatt, Y. F. Houst, A simplified view on chemical effects perturbing the action of superplasticizers, Cem. Concr. Res. 31, 8 (2001) 1169-1176.

[33] M. Nehdi, S. Mindess, P.-C. Aïtcin, Rheology of highperformance concrete: effect of ultrafine particles, Cem. Concr. Res. 28, 5 (1998) 687-697.

[34] R. J. Flatt, Dispersion forces in cement suspensions, Cem. Concr. Res. 34, 3 (2004) 399-408.

[35] P. Stroeven, M. Stroeven, SPACE system for simulation of aggregated matter application to cement hydration, Cem. Concr. Res. 29, 8 (1999) 1299-1304.

[36] M. Sari, E. Prat, J.-F. Labastire, High strength selfcompacting concrete: original solutions associating organic and inorganic admixtures, Cem. Concr. Res. 29, 6 (1999) 813-818.

[37] F. de Larrard, T. Sedran, Optimization of ultra-highperformance concrete by the use of a packing model, Cem. Concr. Res. 24, 6 (1994) 997-1009.

[38] C. Hu, F. de Larrard, The rheology of fresh highperformance concrete, Cem. Concr. Res. 26, 2 (1996) 283294.

[39] W. Aiqin, Z. Chengzhi, Z. Ningsheng, Study of the influence of the particle size distribution on the properties of cement, Cem. Concr. Res. 27, 5 (1997) 685-695.

[40] W. Aiqin, Z. Chengzhi, Z. Ningsheng, The theoretic analysis of the influence of the particle size distribution of cement system on the property of cement, Cem. Concr. Res. 29, 11 (1999) 1721-1726.

[41] R. D. Vanderlei, Análise experimental do concreto de pós reativos: dosagem e propriedades mecânicas, Tese Doutorado em Engenharia de Estruturas, Escola de Engenharia de S. Carlos, Universidade de S. Paulo, S. Carlos, SP (2004).

[42] P. Stroeven, M. Stroeven, Assessment of packing characteristics by computer simulation, Cem. Concr. Res. 29, 8 (1999) 1201-1206.

[43] R. G. Pileggi, Efeito da distribuição granulométrica sobre o comportamento reológico de concretos refratários, Dissertação de Mestrado em Engenharia de Materiais, Universidade Federal de S. Carlos, S. Carlos, SP (1996).

[44] V. Lilkov, E. Dimitrova, S. Gaidardzhiev, Microscopic and laser granulometric analyses of hydrating cement suspensions, Cem. Concr. Res. 29, 1 (1999) 3-8.

[45] J. L. Gallias, R. Kara-Ali, J. P. Bigas, The effect of fine mineral admixtures on water requirement of cement pastes, Cem. Concr. Res. 30, 10 (2000) 1543-1549.

[46] P. K. Mehta, P. J. M. Monteiro, Concreto: estrutura, propriedades e materiais, PINI, S. Paulo (1994).

[47] K. E. Hassan, J. G. Cabrera, R. S. Maliehe, The effect of mineral admixtures on the properties of high-performance concrete, Cem. Concr. Comp. 22, 4 (2000) 267-271.

[48] A. Durekovic, Cement pastes of low water to solid ratio: an investigation of the porosity characteristics under the influence of a superplasticizer and silica fume, Cem. Concr. Res. 25, 2 (1995) 365-375.

[49] C. F. Ferraris, K. H. Obla, R. Hill, The influence of mineral admixtures on the rheology of cement paste and concrete, Cem. Concr. Res. 31, 2 (2001) 245-255.

[50] R. Duval, E. H. Kadri, Influence of silica fume on the workability and the compressive strength of highperformance concretes, Cem. Concr. Res. 28, 4 (1998) 533547.

[51] C. Zhang, A. Wang, M. Tang, X. Liu, The filling role of pozzolanic material, Cem. Concr. Res. 26, 6 (1996) $943-$ 947.

[52] J. Buekett, International admixture standards, Cem. Concr. Comp. 20, 2-3 (1998) 137-140.

[53] M. I. Sánchez de Rojas, J. Rivera, M. Frías, Influence of the microsilica state on pozzolanic reaction rate, Cem. Concr. Res. 29, 6 (1999) 945-949.

[54] P.-C. Aïtcin, A. Neville, How the water-cement ratio affects concrete strength, Concr. Int. 25, 8 (2003) 51-58.

[55] P. Lawrence, M. Cyr, E. Ringot, Mineral admixtures in mortars: effect of inert materials on short-term hydration, Cem. Concr. Res. 33, 12 (2003) 1939-1947.

[56] S. Bhanja, B. Sengupta, Modified water-cement ratio law for silica fume concretes, Cem. Concr. Res. 33, 3 (2003) 447-450.

[57] J. J. Brooks, M. A. Megat Johari, M. Mazloom, Effect of admixtures on the setting times of high-strength concrete, Cem. Concr. Comp. 22, 4 (2000) 293-301.

[58] F. Lange, H. Mörtel, V. Rudert, Dense packing of cement pastes and resulting consequences on mortar properties, Cem. Concr. Res. 27, 10 (1997) 1481-1488.

[59] K. L. Scrivener, R. J. Kirkpatrick, Innovation in use and research on cementitious material, Cem. Concr. Res. 38, 2 (2008) 128-136.

(Rec. 19/01/2008, Rev. 09/04/2008, Ac. 11/04/2008) 